\title{
Kestane Tohumundan (Castanea sativa) Lipaz Enziminin Saflaştırılması ve Kinetik Özelliklerinin İncelenmesi
}

\author{
Bahar BİLGIN SÖKMEN ${ }^{1 *}$ Rıdvan İLGÜN ${ }^{2}$ \\ ${ }^{1}$ Giresun Üniversitesi, Fen Edebiyat Fakültesi, Kimya Bölümü, 28049 Giresun, Türkiye \\ ${ }^{2}$ Giresun Üniversitesi, Merkez Araştırma Laboratuvarı, 28049 Giresun, Türkiye
}

\begin{abstract}
Öz: Bu çallşmada, ülkemizde Giresun İli ve çevresinde bol miktarda yetişen kestane (Castanea Sativa) tohumlarından lipaz enzimi ilk defa saflaştırıld ve kinetik özellikleri incelendi. Petrol eteri ile yağı uzaklaş̧trılmış kestane tohumları 0,06 M sodyum fosfat tamponu ( $p H=7,0)$ ile homojenize edildi. Lipaz esteraz aktivitesi gösteren homojenizattn \% 90'llk $\left(\mathrm{NH}_{4}\right)_{2} \mathrm{SO}_{4}$ kesiti elde edildi. Dializden sonra bu kesit sirasiyla hidroksilapatit ve DEAE-selüloz kolonlara uygulanarak lipaz enzimi 186,87 kez saflaşttrild. SDS-PAGE elektroforezi sonucunda saflaşttrilan enzimin molekül ağırlı̆̆ının $30 \mathrm{kDa}$ olduğu bulundu. Kestane tohumlarından saflaştırılan lipazın optimum pH'ssınin 9,0; optimum sıcaklğ̆ının 30 ${ }^{\circ} \mathrm{C}$ olduğu bulundu. Enzimin çeşitli substratlara karşı ilgisi incelendiğinde, lipazın ilgisinin en çok p-NFM'a olduğu ve $K_{m}$ ve $V_{\max }$ değerlerinin sirastyla 1,017 mM ve 163,874 U olduğu saptand.
\end{abstract}

Anahtar sözcükler: Kestane (Castanea sativa) tohumu, lipaz, karakterizasyon, saflaștırma

Atıf yapmak için: Bilgin Sökmen, B. \& İlgün, R. (2018). Kestane tohumundan (Castanea sativa) lipaz enziminin saflaştırılması ve kinetik özelliklerinin incelenmesi. Anadolu Çev. ve Hay. Dergisi, 3(3), 101-106.

\section{Lipase Purification from the Seeds of chestnut (Castanea sativa) and Its Investigation of Some Kinetic Properties}

\begin{abstract}
In this study, lipase was firstly purified from chestnut (Castanea sativa) seeds, being abundant in Giresun (Turkey) and surroundings and the kinetic properties of the enzyme were investigated. Chestnut seeds, being fat-free with petroleum ether extraction, were homogenized with $0.06 \mathrm{M}$ sodium phosphate buffer ( $\mathrm{pH}=7.0) 90 \%$ of $\left(\mathrm{NH}_{4}\right)_{2} \mathrm{SO}_{4}$ fraction of lipase esterase activity homogenate was obtained. After dialysis, this fraction was applied respectively to hydroxyapatite and DEAE-cellulose columns, and lipase was purified 186.87 times. The purified enzyme, which showed SDS-PAGE, had a molecular weight of $30 \mathrm{kDa}$. It was found that the lipase purified from chestnut seeds had an optimum pH value of 9.0 and an optimum temperature of $30^{\circ} \mathrm{C}$. When affinity against various substrates of the enzyme is investigated, lipase affinite was found that have to $p$-NPM and its $K_{m}$ and $V_{\max }$ values were dedected $1.017 \mathrm{mM}$ and $163.874 \mathrm{U}$, respectively.
\end{abstract}

Keywords: Kestane (Castanea sativa) tohumu, lipaz, karakterizasyon, saflaștırma

How to cite: Bilgin Sökmen, B. \& İlgün, R. (2018). Lipase purification from the seeds of chestnut (Castanea sativa) and its investigation of some kinetic properties. $J$. Anatolian Env. and Anim. Sciences, 3(3), 101-106.

\section{GİRIŞ}

Lipazlar (E.C.3.1.1.3; trigliserol açilhidrolazlar), triaçilgliserollerin serbest yağ asitlerine ve gliserole hidrolizini katalizleyen enzimlerdir. Endüstride ve bilimsel araştırmalarda; hidroliz, esterleşme, trans esterleşme, peptid sentezi gibi reaksiyonları ve bölge seçimli, stereo seçimli mekanizmaları katalizlemekte kullanılırlar (Sharma vd., 2001). Lipazlar, birçok tepkimeyi katalizleyebilme becerileri ile endüstride deterjan, gıda, deri, kağıt, kozmetik ve farmasötik alanlarda geniş bir kullanıma sahiptirler. Hidrolitik lipazların başlıca ticari kullanım alanı deterjanlardır. Toplam lipaz kullanımının \%32'si deterjan endüstrisinde gerçekleşmektedir (Paiva vd., 2000). Lipaz kullanım alanlarına süt ürünleri, unlu mamüller, içecekler, yiyecek sosları, et ve balık ürünleri, yağlar, kimyasallar ve temizlik ürünlerinde ilave edilmelidir (Şengel, 2007).
Hidrolitik enzimler arasında lipazlar en geniş kullanım alanına sahip enzimlerdir (Ünlü, 2004). Lipazlar kullandıkları substratların çeşitliliği ve ekstrem koşullarda (sıcaklık, pH, organik çözücüler gibi ortamlarda) kararlı yapılarını koruyabilme sebeplerinden dolayı önemli biyokatalizörler arasındadırlar (Gupta vd., 2004; Hasan vd., 2006).

Bitkisel yağlı tohumlardan lipaz izolasyonu ve saflaştırılması üzerine literatürde çeşitli çalışmalar yapılmıştır (Bilgin Sökmen, 2005; Yeşiloğlu \& Başkurt, 2008). Kestane tohumu bileşiminde de, proteinler ve yağlar gibi önemli besin ve bileşenler bulunmaktadır. Kayıngiller familyasında yer alan kestane, botanik sistematiğinde Fagales Takımına ait olup, Castanea Cinsi ve Castanea spp. türü olarak yerini almaktadır (Subaşı, 2004). 
Lipazlar birçok bitkisel, hayvansal ve özellikle mikroorganizmalardan saflaştırılmasına rağmen, bugüne kadar kestane tohumlarından saflaştırılmamıştır. Bu çalışmada, Giresun'da yetişen kestane tohumundan $(C$. sativa) lipaz enzimi ilk defa saflaştırılmış ve kinetik özellikleri üzerine araştırmalar yapılmıştır. $\mathrm{Bu}$ amaçla kestaneden lipaz enzimi çeşitli yöntemleriyle saflaştırılarak optimum sicaklık, optimum $\mathrm{pH}$, termal kararlılık, substrat spesifitesi, $K_{m}$ ve $V_{\max }$ değerleri gibi kinetik özellikleri esteraz aktivitesine göre tayin edilmiştir.

\section{MATERYAL ve METOD}

Ham Ekstrenin Hazırlanması, Amonyum Sülfat Çöktürmesi, Dializ, Hidroksil Apatit ve Dietilaminoetil (DEAE)-Selüloz Kolon Kromatografileri: Ham ekstre hazırlamak için Blender yardımıyla parçalanmış kestane 1:7 (w/v) oranında $60 \mathrm{mM}$ fosfat tamponu $(\mathrm{pH}=7,0)$ içinde +4 ${ }^{\circ} \mathrm{C}$ 'de manyetik karıştırıcı ile 1 saat karıştırıldıktan sonra, ağzı kapatılarak bir gece bekletildi. Ertesi gün homojenizat iki kat bezden süzüldü. $0{ }^{\circ} \mathrm{C}^{\prime}$ de 18000 rpm'de, 30 dakika santrifüj edildi. Üstteki berrak kısım alındı. Bu işlemlerin sonucunda Kestane tohumu ham ekstresi elde edildi. Ham ekstrede lipaz esteraz aktivitesi ve protein miktar tayinleri yapıld1.

Kestane tohumu lipazı için uygun amonyum sülfat konsantrasyonunu saptamak üzere \% 10-90 konsantrasyon aralığında çöktürme yapıldı. Amonyum sülfatı uzaklaştırmak amacıyla $+4{ }^{\circ} \mathrm{C}$ 'de dializ edildi. Hidroksil apatit kolonuna yaklaşı 203,5 mg/mL protein olarak \% 90 amonyum sülfat kesiti uyguland. Kolondan sirasiyla $5 \mathrm{mM}$, $10 \mathrm{mM}, 50 \mathrm{mM}, 100 \mathrm{mM}$ ve $200 \mathrm{mM}$ sodyum fosfat tamponları $(\mathrm{pH}=7,0)$ geçirilerek gerçekleştirildi. DEAEselüloz kolonuna hidroksilapatit kolonundan elde edilen 100 mM'lı fraksiyon eluatı uygulandı. Kolondan sirasıyla yaklaşık $200 \mathrm{~mL} 0,5 \mathrm{mM}$ fosfat tamponunda çözülmüş 1 $\mathrm{mM}, 5 \mathrm{mM}, 10 \mathrm{mM}, 50 \mathrm{mM}$ ve $100 \mathrm{mM} \mathrm{NaCl}$ gradienti uyguland1.

Lipaz Esteraz Aktivitesi ve Protein Tayini: Lipaz enzimi esteraz ve hidrolaz olmak üzere iki farklı aktiviteye sahiptir. Çalışmamızda Kestane tohumu lipaz esteraz aktivitesi, substrat olarak p-nitrofenil asetat (p-NFA) kullanılarak spektrofotometrik olarak yapıldı (Erlanson, 1970). Bir deney tüpüne substrat ve enzim çözeltilerinden 0,5'er $\mathrm{mL}$ alınıp 0,5 mL 0,5 M Tris- $\mathrm{HCl}$ tamponu ilave $(\mathrm{pH}=7,4)$ edildi. Karışım oda sıcaklığında 5 dakika inkübe edilip spektrofotometrede, $400 \mathrm{~nm}$ 'de, absorbans ölçüldü. $\mathrm{Bu}$ absorbans değerinin p-nitrofenol regresyon denklemine uygulanmasıyla enzim tarafından, oda sicaklığında, 1 dakikada açığa çıkarılan p-nitrofenol miktarı $\mu \mathrm{mol} /$ dakika olarak belirlendi.
Kestane tohumundan lipaz saflaştırılmasının tüm adımlarında, protein miktarı tayin edildi (Lowry, vd., 1951). Hidroksiapatit ve DEAE-selüloz kolon kromatografileri ile elde edilen fraksiyonlardaki protein miktar tayinlerinde ise $\mathrm{E}_{280} / \mathrm{E}_{260}$ yöntemi kullanıldı (Warburg \& Christian, 1941).

Sodyum Dodesil Sülfat-Poliakrilamid Jel Elektroforezi (SDS-PAGE) ile Enzim Saflı̆̆ının Kontrolü: Kestane lipazı, DEAE-selüloz kolon kromatografisi ile saflaştırıldıktan sonra yığma jeli \% 3, ayırma jeli ise \% 10 konsantrasyonlarında olacak şekilde kesikli SDS-PAGE jel elektroforezi ile enzimin saflık derecesi kontrol edildi (Laemmli, 1970). Enzimin molekül ağırlığı standart proteinlerin molekül ağırlıkları yardımıyla grafikten hesapland1.

Kinetik Özelliklerin Incelenmesi: Kestane tohumundan elde edilen lipazın esteraz aktivitesine göre kinetik özelliklerini, sıcaklık ve pH etkisini incelemek için DEAE-selüloz kolonundan elde edilen fraksiyonlar kullanıldı.

Esteraz Aktivitesi $\ddot{U} z e r i n e ~ p H$ etkisi ve pH Stabilitesinin Incelenmesi: Kestane tohumu lipazının optimum pH'sını belirlemek amacıyla $\mathrm{pH}=4-12$ aralığında gösterdiği esteraz aktivitesi ölçüldü. $\mathrm{pH}=4-5$ aralığında asetat tamponu, $\mathrm{pH}=6-8$ aralığında fosfat tamponu, $\mathrm{pH}=9-10$ aralığında glisin- $\mathrm{NaOH}$ tamponu, $\mathrm{pH}=11-12$ aralığında ise $\mathrm{Na}_{2} \mathrm{HPO}_{4}-\mathrm{NaOH}$ tamponu kullanıldı. Tüm denemeler oda sıcaklığında gerçekleştirildi. Denemeler $3 \mathrm{kez}$ yapılarak ortalamaları alındı. Değişik pH değerlerinde elde edilen esteraz aktivitesi optimum $\mathrm{pH}$ eğrisi çizildi.

Lipaz enziminin $\mathrm{pH}$ stabilite özelliğini belirlemek amacıyla; enzimin $\mathrm{pH}=4,0-12,0$ aralığında, 20, 40, 60, 80, 100 ve 120 dakika süreyle inkübasyonu sonrası koruduğu esteraz aktivitesi değerleri, $100 \mathrm{mM}$ p-nitrofenil asetat substratı kullanılarak tayin edildi. Her bir pH'daki bekleme süresi sonunda yapılan ölçümlerden elde edilen aktivite değerleri \% aktiviteye dönüştürüldü. Zamana karşı \% korunan aktivite grafiği çizildi.

Optimum Sicaklik ve Termal Stabilitenin Incelenmesi: Enzim çözeltisinden 3 'er $\mathrm{mL}$ alınarak $10-70^{\circ} \mathrm{C}$ arasında, sicaklık her defasında $10{ }^{\circ} \mathrm{C}$ arttırılarak, su banyosunda 30 dakika süre ile tutuldu. Oda sicaklığına getirilen çözeltilerde lipaz aktivitesi tayin edildi. Denemeler $3 \mathrm{kez}$ tekrarlanarak \% aktivite değerleri hesaplandı.

Lipaz enziminin termal stabilite özelliğini belirlemek amaciyla; enzimin $10-70{ }^{\circ} \mathrm{C}$ s1caklıklarda 20-120 dakika süreyle inkübasyonu sonrası koruduğu esteraz aktivitesi değerleri ölçüldü. Her bir sicaklıktaki bekleme süresi sonunda yapılan ölçümlerden elde edilen aktivite 
değerleri \% aktiviteye dönüştürüldü. Zamana karş1 \% korunan aktivite grafiği çizildi.

$K_{m}$ ve $V_{\max }$ Değerlerinin Hesaplanması: Kestane tohumundan saflaştırılan lipaz enziminin sadece p-NFA'a ilgisinin fazla olduğu saptandığından bu enzimin p-nitrofenil asetat için $\mathrm{K}_{\mathrm{m}}$ ve $\mathrm{V}_{\max }$ değerleri tayin edildi. $\mathrm{Bu}$ amaçla $\mathrm{p}$ NFA, p-nitrofenil bütirat ( $\mathrm{p}-\mathrm{NKB})$, p-nitrofenil kaprat ( $\mathrm{p}$ NFK), p-nitrofenil laurat ( $\mathrm{p}-\mathrm{NFL}$ ) ve p-nitrofenil miristat ( $\mathrm{p}$ NFM)' in 0,25 mM, 0,5 mM, 2,0 mM, 4,0 mM, 6,0 mM ve 8,0 mM'lık izopropil alkoldeki çözeltileri hazırlandı. Enzim aktivitesi Vonderwulbecke ve diğ. (1992) ile Winkler ve Stuckman (1979)'ın yöntemleri değiştirilerek tayin edildi (Vonderwulbecke vd., 1992; Winkler \& Stuckman; 1979). Deneyler 10 defa tekrarlandı. En küçük kareler yöntemine göre Lineweaver-Burk doğru denkleminden ve grafikten pNFA için $K_{m}$ ve $V_{\max }$ değerleri hesaplandı.

\section{BULGULAR}

Kestane tohumu ham ekstresinde lipazı çöktüren uygun amonyum sülfat konsantrasyonunun \% 90 olduğu belirlendi. Hidroksilapatit kolonunda kestane tohumu için yüksek lipaz aktivitesi $100 \mathrm{mM}$ fosfat tamponu ile elde edilen elüatlarda bulundu (Şekil 1). En yüksek lipaz aktivitesi gösteren tüplerdeki elüatlar daha ileri bir saflaştırma için DEAE-selüloz kolonuna tatbik edildi.

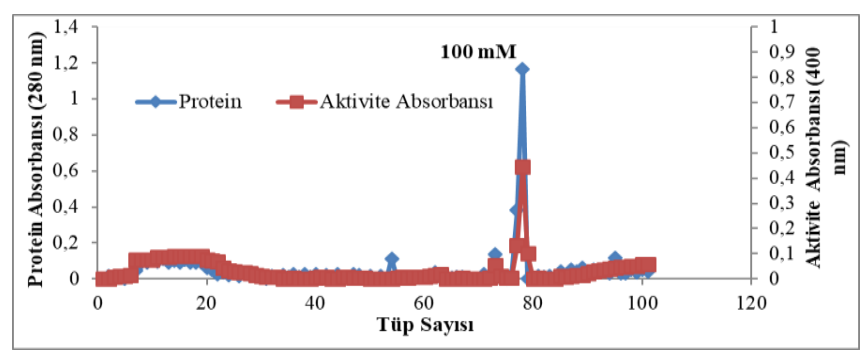

Şekil 1. Kestane Tohumu Ham Ekstresinin \% 90 Amonyum Sülfat Fraksiyonunun Hidroksilapatit Kolon Kromatografisi Elüsyon Grafiği.

Hidroksilapatit kolon çıkışlı $100 \mathrm{mM}$ fosfat eluatının DEAE-selüloz kolonuna uygulanması sonucunda lipazın $1 \mathrm{mM} \mathrm{NaCl} / 0,5 \mathrm{M}$ sodyum fosfat tamponu ile tek pik şeklinde olduğu gözlemlendi (Şekil 2).

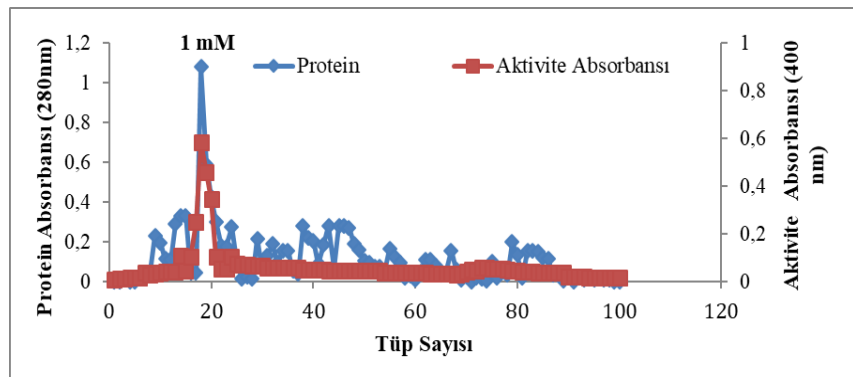

Şekil 2. Hidroksilapatit Kolonu 100 Mm'lık Elüatının DEAESelüloz Kolon Kromatografisi Elüsyon Grafiği.
Kestane tohumlarından lipazın saflaştırılma adımları ve bu adımlardaki aktivite ve saflaşma kat sayıları Tablo 1'de gösterildi. Çalışmamızda kestane tohumu ham ekstresi hazırlama, amonyum sülfat kesiti, hidroksilapatit ve DEAE-selüloz kolon kromatografisi evrelerinde lipaz aktivitesi, esteraz aktivitesi olarak tayin edildi. Kestane tohumlarından lipaz enzimi DEAE- selüloz kolon kromatografisi sonucu 186,87 kez saflaştırıldı (Tablo 1).

Tablo 1. Kestane Tohumlarından Lipazın Saflaştırılma Adımlarının Esteraz Aktivitesine Göre İncelenmesi.

\begin{tabular}{lcccc}
\hline İslem Evreleri & $\begin{array}{c}\text { Total Protein } \\
(\mathrm{mg})\end{array}$ & $\begin{array}{c}\text { Total Aktivite Spesifik Aktivite } \\
(\mathrm{U})\end{array}$ & $\begin{array}{c}\text { Saflaştırma } \\
\text { (U/mg) }\end{array}$ & Oranı \\
\hline Ham Ekstre & 7432 & 198754 & 26,74 & 1 \\
\hline \%60 Amonyum Sülfat Kesiti & 501 & 12507 & 13,49 & 1,03 \\
\hline Dializat & 158 & 4817 & 30,49 & 1,14 \\
\hline Hidroksilapatit Kolon Kromatografisi & 38 & 9200 & 242,11 & 9,05 \\
\hline DEAE-Selüloz Kolon Kromatografisi & 14 & 69958 & 4997 & 186,87 \\
\hline
\end{tabular}

SDS-PAGE Elektroforezi: Saflaştırılan lipaz enziminin SDS-PAGE uygulanarak tek protein band1 içerdiği saptandı. Molekül ağırlığı tayininde kullanılan standart proteinler ile çizilen eğriden lipazın molekül ağırlığının 30 kDa olduğu saptandı. (Şekil 3.).

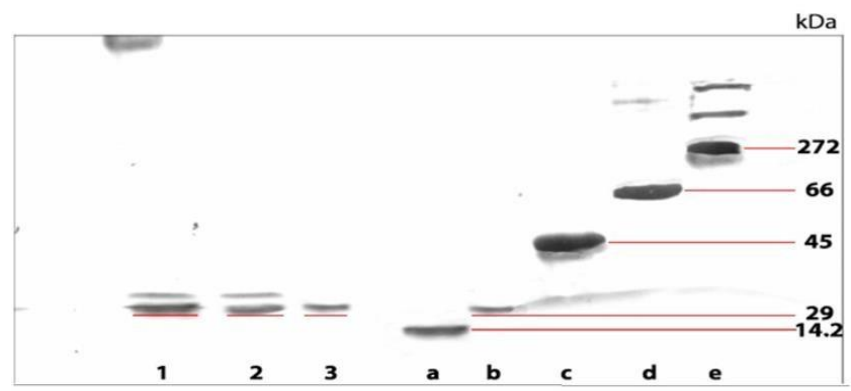

Şekil 3. SDS-PAGE jel elektroforezi.

1. Ham ekstre, 2. Hidroksi apatit eluatı, 3. DEAE-selüloz enzim çözeltisi, a. Bovine milk laktalbumin $(\mathrm{Mr}=14.2 \mathrm{kDa}), \mathrm{b}$. Karbonik anhidraz $(\mathrm{Mr}=29$ $\mathrm{kDa})$, c. Albumin $(\mathrm{Mr}=45 \mathrm{kDa})$, d. Serum albumin $(\mathrm{Mr}=66 \mathrm{kDa}$ monomer, $\mathrm{Mr}=132 \mathrm{kDa}$ dimer), e. Fasülyeden elde edilen üreaz ( $\mathrm{Mr}=272$ $\mathrm{kDa}$ trimer, $545 \mathrm{kDa}$ hekzamer).

Lipaz Esteraz Aktivitesine pH'nın Etkisi ve pH Stabilitesi: Farklı pH'larda ( $\mathrm{pH}=4-12)$ lipaz aktivitesinin 400 nm'de, $100 \mathrm{mM}$ p-NFA substratı kullanılarak esteraz aktivitesi incelenmesi sonucunda kestane tohumu lipazının en yüksek aktiviteyi $\mathrm{pH}=9$ 'da gösterdiği, $\mathrm{pH}=10$ 'dan sonra aktivitenin azaldığı görüldü (Şekil 4).

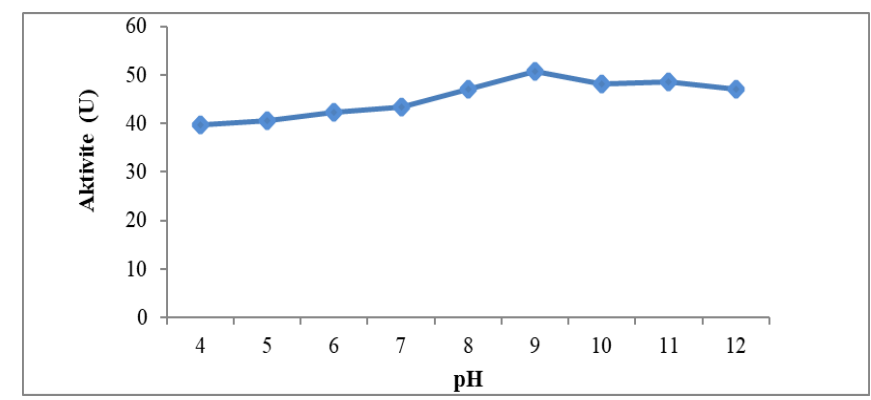

Şekil 4. Lipaz esteraz aktivitesi üzerine pH'nın etkisi. 
Esteraz aktivitesinin pH'a bağımlı stabilitesini belirlemek amaciyla hesaplanan aktivitelere göre çizilen grafikte $\mathrm{pH}=10$ 'da enzim aktivitesinin en yüksek olduğu ve zamana bağlı olarak aktivitenin 100. dakikadan sonra az da olsa arttığı saptandı. Diğer pH'larda önemli farklılıklar görülmedi (Şekil 5).

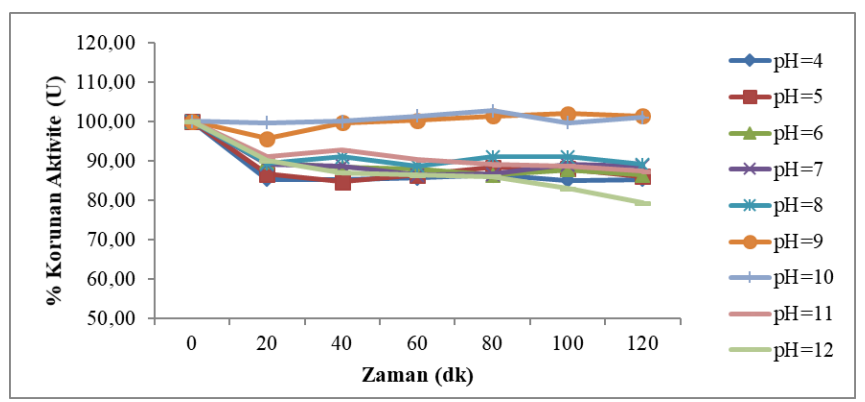

Şekil 5. Lipaz Esteraz Aktivitesinin pH Stabilitesi.

Lipaz Esteraz Aktivitesine Sicaklı̆̆ın Etkisi: Sıcaklığın lipaz aktivitesi üzerine etkisi $10-70{ }^{\circ} \mathrm{C}$ arasında pNFA substratı kullanılarak incelendiğinde, en yüksek aktivitenin $30^{\circ} \mathrm{C}$ 'de olduğu bulundu. Sicaklığın daha da artmasıyla aktivitenin azaldığı saptandı (Şekil 6).

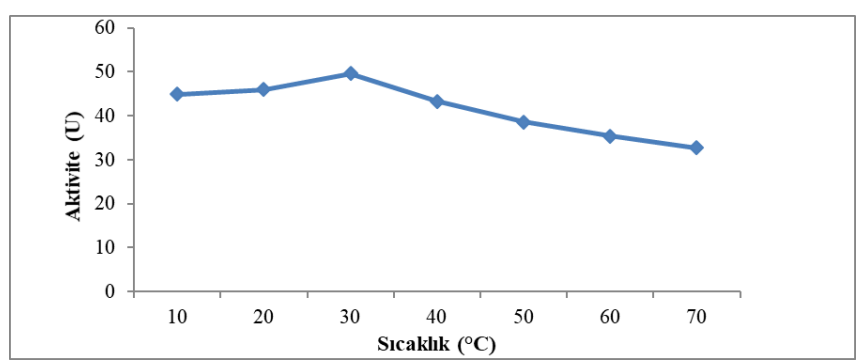

Şekil 6. Lipaz esteraz aktivitesi üzerine sıcaklığın etkisi.

Lipaz Esteraz Aktivitesinin Termal Stabilitesi: Lipazın sıcaklığa bağımlı stabilitesini belirlemek amacıyla $10-70^{\circ} \mathrm{C}$ arasındaki sicaklıklarda 20,40, 60, 80, 100 ve 120. dakikalardaki bekleme süreleri sonucunda hesaplanan aktivitelere göre çizilen grafiklerden lipazın aktivitesinin tüm sıcaklıklarda bekleme sürelerindeki aktivite değerlerinde çok azalma olduğu saptandı. En yüksek aktivite kaybı 100. dakikadan sonra görüldü (Şekil 7).

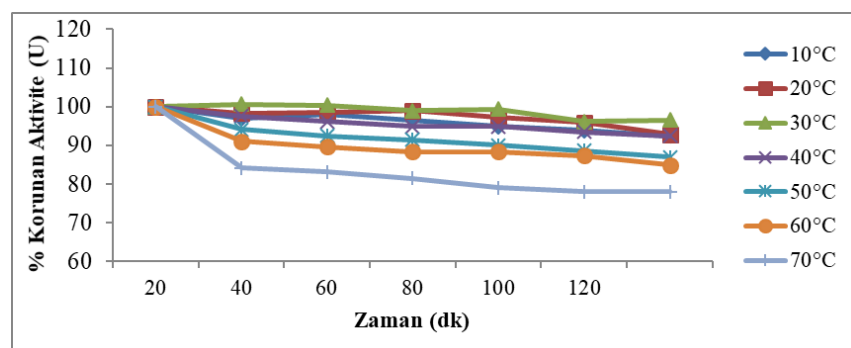

Şekil 7. p-Nitrofenil asetatın sıcaklık stabilitesi.

Lipazın Farklı Subsratlara Göre $K_{m}$ ve $V_{\text {max }}$ Değerleri: Lipaz enziminin farklı substratları için $K_{m}$ ve $\mathrm{V}_{\max }$ değerleri Lineweaver-Burk denkleminden yararlanılarak hesaplandı (Tablo 2). Tablo 2'deki değerlerden anlaşılacağı üzere lipazın substrat olarak en fazla ilgisinin p-NFM'a olduğu görüldü.

Tablo 2. Kestane tohumu lipazının farklı substratları için $\mathrm{K}_{\mathrm{m}}$ ve $\mathrm{V}_{\max }$ değerleri.

\begin{tabular}{lll}
\hline Substrat & $\mathbf{K}_{\mathbf{m}}(\mathbf{m M})$ & $\mathbf{V}_{\max }(\mathbf{U})$ \\
\hline p-NPA & 1,579 & 526,31 \\
p-NPB & 1,176 & 285,71 \\
p-NPC & 1,064 & 212,76 \\
p-NPL & 1,042 & 178,57 \\
p-NPM & 1,017 & 166,66 \\
\hline
\end{tabular}

\section{TARTIŞMA ve SONUÇ}

Endüstrinin çeşitli alanlarında (Margarin, süt ve yă̆ endüstrisi, deterjan ve gıda endüstrisi, ilaç ve saf kimyasalların sentezi, kağıt imalatı, kozmetik endüstrisi, eczacılık ve tekstil gibi) kullanıma sahip olan lipazların, çeşitli bitki, hayvan ve mikroorganizmalardan saflaştırıldığ ve bazı kinetik özelliklerinin incelendiği bildirilmektedir. Lipazın kestane tohumundan saflaştırılması ile ilgili literatürlerde herhangi bir çalışmaya rastlanmamıştır. $\mathrm{Bu}$ çalışmada, kestane tohumu lipazı ilk kez saflaştırılmış ve bazı kinetik özellikleri incelenmiştir.

Enzimlerin çeşitli bitki, hayvan ve mikroorganizmalardan saflaştırılmasında, farklı yöntemler kullanılmaktadır. $\mathrm{Bu}$ yöntemlere göre çalışmalarda saflaştırma oranları da değişmektedir. Yapılan çalışmalarda lipaz, pirinç kepeğinden 7,6 kat (Bhardwaj vd., 2001), ayçiçek tohumundan 603 kat (Beisson vd., 1997), Aspergillus niger'den 50 kat (Namboodiri \& Chattopadyay, 2000) sütten izole edilen Serratia marcescens'ten 20,88 kat (Abdou, 2003) saflaştırılmıştır. Çalışmamızda kestane tohumu lipazı 186,87 kat saflaştırılmıştır.

Lipazın saflaştırılması evrelerinde, ham ekstre ve DEAE-selüloz kolon kromatografisi çıkışlı enzim örneklerinde yapılan SDS-PAGE sonucunda, ham ekstrenin birden fazla protein bandı içerdiği, DEAE-selüloz kolon kromatografisi sonucu elde edilen lipaz enziminin ise 30 kDa molekül ağırlığına sahip tek bir protein bandı içerdiği görüldü. Bitki lipazları ile ilgili yapılan çalışmalarda, lipazların molekül ağırlıklarının nispeten küçük olduğu, örneğin; Jatropha curcas L. tohum lipazının molekül ağırlığının 21,6 (Staubmann vd., 1999) pirinç kepeğinin 9,4 kDa (Prabhu vd., 1999), ayciçek tohum lipazının 22 kDa (Beisson vd., 1997), olduğu bildirilmektedir.

Enzim aktivitesi üzerine pH'nın etkisi ve dayanıklılı̆̆ kestane tohumu lipazının optimum pH'sının 9,0 olduğu saptand1. Enzimin $\mathrm{pH}$ dayanıklılı̆̆ incelendiğinde ise; $\mathrm{pH}=$ 4-12 aralığında enzimin 20 ile 120 dakika inkübe 
edilmesinden sonra, lipazın en yüksek aktivite değerlerinin pH=9-10 arasında olduğu görüldü.

Bitkisel kaynaklı yağlı tohumların lipaz aktivitesine etki eden $\mathrm{pH}$ değerleri üzerine yapılan çalışmalarda, kestane tohum lipazının optimum pH'sı 8-9, ayçiçek tohum lipazının optimum pH'sı 8-9 (Beisson vd., 1997), pirinç kepeği lipazının optimum pH'sı 7-7,5 (Prabhu vd., 1999), Umbellularia californica tohumlarından saflaştırılan lipazın optimum pH's1 8,5 olarak (Haas vd., 2001) bulunmuştur. Kestane tohumu lipazının $\mathrm{pH}$ stabilitesi incelendiğinde enzim stabilitesinin $\mathrm{pH}$ 9'da en yüksek olduğu görülmektedir. Saflaştırılan enzimin optimum $\mathrm{pH}$ değeri ve dayanıklılığından bazik yapıda bir enzim olduğu söylenebilir.

Bitkisel kaynaklı yağlı tohumlar üzerine yapılan çalışmalarda lipaz aktivitesinin sıcaklık etkisi ve dayanıklılığı değerlendirildiğinde optimum sıcaklığın 30$60^{\circ} \mathrm{C}$ arasında, sicaklık stabilitesinin de farklı sicaklık değerleri arasında olduğu görülmektedir (Haas vd., 2001). Kestane tohumundan saflaştırılan lipazın $25^{\circ} \mathrm{C}$ (Bilgin Sökmen, 2005), palm yağı (Elaeis guineensis)'ndan saflaştırılan lipazın optimum sıcaklığının $30^{\circ} \mathrm{C}$, acı bakladan saflaştırılan lipazın ise $25^{\circ} \mathrm{C}$ olduğu bildirilmiştir (Sanz \& Olais, 1990). Ayrıca literatürde enzimin $70^{\circ} \mathrm{C}$ sıcaklığa karşı bile stabil olduğu bulunmuştur (Dharmsthiti \& Ammaranond, 1997). Kestane lipazının sıcaklık stabilitesi incelendiğinde enzimin $10-70^{\circ} \mathrm{C}$ arasında farklı inkübasyon sürelerinde dahi kararlı olduğu (fazla bir aktivite kaybının olmadığı) görülmüştür.

Bu çalışmada, sıcaklık ve pH stabilitesi göz önüne alındığında enzimin sıcaklığa dayanıklı bir enzim olduğu ve pH stabilitesinin de kararlı bir yapıda olduğu söylenebilir. Uygun enzim konsantrasyonu, substrat ve reaksiyon sürelerinin tayininde bulduğumuz değerler, enzim aktivitesinin uygun reaksiyon şartlarında yapıldığını göstermektedir.

Sonuç olarak, ülkemizde yetişen ve yurt dişına ihraç edilen kestane tohumlarından lipaz enziminin saflaştırılıp çeşitli endüstri alanlarında kullanılabileceği kanısındayı.

\section{TEŞEKKÜR}

$\mathrm{Bu}$ çalışma, Giresun Üniversitesi Bilimsel Araştırma Koordinasyon Biriminin FEN-BAP-A-220413-43 numaralı projesi ile desteklenmiştir.

\section{KAYNAKLAR}

Abdou, M. A. (2003). Purification and partial characterization of psychrotrophiz Serratia marcescens lipase. Journal of Dairy Science, 86(1), 127-132. doi: 10.3168/jds.S0022-0302(03)73591-7

Beisson, F., Gardies, A.M., Teissere, M., Ferte, N. \& Noat, G. (1997). An esterase neo synthesized in post-germinated sunflower seeds is related to a new family of lipolytic enzymes. Plant Physiology and Biochemistry, 35(10), 761-765.

Bhardwaj, K., Raju, A. \& Rajasekharan, R. (2001). Identification, purification, and characterization of a thermally stable lipase from rice bran. a new member of the (phospho) lipase family. Plant Physiology, 127(4), 1728-1738. doi: 10.1104/pp.010604

Bilgin Sökmen, B. (2005). Kayısı (Armeniaca vulgaris Lam.) tohumlarından lipazın saflaştırılması ve çeşitli taşlyıcılara immobilize edilmesi. Doktora Tezi, İstanbul Üniversitesi, Fen Bilimleri Enstitüsü, İstanbul, Türkiye, 137s.

Dharmsthiti, S. \& Ammaranond, P. (1997). Purification and characterization of lipase from a raw-milk yeast (Trichosporon asteroides). Biotechnology and Applied Biochemistry, 26(2), 111-116. 10.1111/j.1470-8744.1997.tb00455.x.

Erlanson, C. (1970). p-Nitrophenylacetate as a substratefor a carboxyl-ester hydrolase in pancreatic juice and intestinal content. Scandinavian Journal of Gastroenterology, 5(5), 333-336.

Gupta, R., Gupta, N. \& Rathi, P. (2004). Bacterial lipases: An overview of production, purification and biochemical properties. Applied Microbial Biotechnology, 64(6), 763-781. doi: 10.1007/s00253-004-1568-8.

Haas, M.J., Cichowicz, D.J. \& Dierov, J.K. (2001). Lipolytic activity of californica-laurel (Umbellularia californica) seeds. Journal of American Oil Chemist's, 78(10), 1067-1071. doi: 10.1007/s11746-001-0390-0.

Hasan, F., Aamer, A.S. \& Hameed, A. (2006). Industrial applications of microbial lipases. Enzyme and Microbial Technology, 39(2), 235-251. doi: 10.1016/j.enzmictec.2005.10.016.

Laemmli, U.K. (1970). Cleavage of structural proteins during the. aassembly of the head of bacteriofage T4. Nature, 227(5259), 680-685. doi: 10.1038/227680a0.

Lowry, O.H., Rosebrough, N.J., Farr, A.L. \& Randall, R.J. (1951). Protein measurement with folin phenol reagent. Journal of Biological Chemistry, 193(1), 265-275. 
Namboodiri, V.M.H. \& Chattopadhyay, A. (2000). Purification and biochemical characterization of a novel thermostable lipase from Aspergillus niger. Lipids, 35(5), 495-502.

Paiva, A.L., Balcao, V.M. ve Malcata, F.X. (2000). Kinetics and mechanisms of reactions catalyzed by immobilized lipases. Enzyme and Microbial Technology, 27(3-5), 187-204. doi: 10.1016/S01410229(00)00206-4.

Prabhu, V.A., Tambe, S.P., Gandhi, N.N., Sawant, S.B. \& Joshi, J.B. (1999). Rice bran lipase: extraction, activity and stability. Biotechnology Progress, 15(6), 1083-1089. doi: 10.1021/bp990122z.

Sanz, L.C. \& Olais, J.M. (1990). Characterization of lupin seed lipase. Food Chemistry, 37(3), 221-228. doi: 10.1016/0308-8146(90)90139-U.

Sharma, R., Chisti, Y., Banerjee, U.C. (2001). Research Review Paper: Production, purification, characterization, and applications of lipases. Biotechnology Advances, 19(8), 627-662. doi: 10.1016/S0734-9750(01)00086-6.

Staubmann, R., Ncube, I., Gubitz, G.M, Steiner, W. \& Read, J.S. (1999). Esterase and lipase activity in Jatrophacurcas L. seeds. Journal of Biotechnology, 75, 117-126. doi: 10.1016/S0168-1656(99)00151-0.

Subaşı, B. (2004). Kestane Sektör Profili, İstanbul Ticaret Odası Etüt ve Araştırma Şubesi, İstanbul.

Şengel, B. (2007). Deterjan katki maddesi olarak mikrobiyal kaynakli lipaz üretim koşullari. Yüksek Lisans Tezi, Ankara Üniversitesi Fen Bilimleri Enstitüsü, Ankara, Türkiye, 174s.

Ünlü, A.E. (2004). Candida Rugosa Lipazının özellikleri ve enantiyo seçimliliğinin arttırlması. Seminer. Ankara Üniversitesi, Kimya Mühendisliği Anabilim Dalı, Ankara, Türkiye.
Vorderwulbecke, T., Kieslich, K. \& Erdmann, H. (1992). Comparison of lipases by different assays. Enzyme and Microbial Technology, 14(8), 631-639. doi: 10.1016/0141-0229(92)90038-P.

Yeşiloğlu, Y. \& Başkurt, L. (2008). Partial purifacation and characterization of almond seed lipase. Preparative Biochemistry Biotechnology, 38(4), 397-410. Doi: 10.1080/10826060802325592.

Warburg, O. \& Christian, W. (1941). Isolierungund kristallinsation des garungsferments enolase. Biochemische Zeitschrift, 310(6), 384-421.

Winkler, U. K. \& Stuckmann, M. (1979). Glycogen, hyaluronate, and some other polysaccaharides greatly enhance the formation of exolipase by Serratia marcescens. Journal of Bacteriology, 138(3), 663-670. doi: 0021-9193/79/060663/08\$02.00/0.

Received date: 18.04 .2018

Accepted date: 12.06 .2018

*Corresponding author's:

Bahar BİLGIN SÖKMEN

Giresun Üniversitesi, Fen Edebiyat Fakültesi,

Kimya Bölümü, 28049/Giresun, Türkiye

E-mail: bahar.sokmen@ giresun.edu.tr

ORCID: https://orcid.org/0000-0003-3904-8178 